\title{
BMJ Open Does sector matter for the quality of care services? A secondary analysis of social care services regulated by the Care Inspectorate in Scotland
}

\author{
Anders Malthe Bach-Mortensen, ${ }^{1}$ Paul Montgomery ${ }^{2}$
}

To cite: Bach-Mortensen AM, Montgomery P. Does sector matter for the quality of care services? A secondary analysis of social care services regulated by the Care Inspectorate in Scotland. BMJ Open 2019;9:e022975. doi:10.1136/ bmjopen-2018-022975

- Prepublication history and additional material for this paper are available online. To view these files, please visit the journal online (http://dx.doi org/10.1136/bmjopen-2018022975).

Received 15 March 2018 Revised 4 December 2018 Accepted 6 December 2018

Check for updates

(c) Author(s) (or their employer(s)) 2019. Re-use permitted under CC BY-NC. No commercial re-use. See rights and permissions. Published by BMJ.

${ }^{1}$ Department of Social Policy and Intervention, University of Oxford, Oxford, UK

${ }^{2}$ Department of Social Policy, Sociology and Criminology, University of Birmingham, Birmingham, UK

\section{Correspondence to}

Anders Malthe Bach-Mortensen; anders.bach-mortensen@spi.

ox.ac.uk,

a.m.bachmortensen@gmail.com

\section{ABSTRACT}

Objectives Social services are increasingly commissioned to third and for-profit sector providers, but little is known about whether and how these changes influence quality indicators. We assessed quality-related outcomes across for-profit, public and third sector organisations delivering social care services.

Design A secondary analysis was conducted on publically available data collected by the independent regulator of social care organisations in Scotland. All outcomes are reported as predicted probabilities derived from multivariate logistic regression coefficients. Generalised ordered logit models are utilised for the quality domains and the risk assessment score and logistic regression for whether complaints or requirements were issued to organisations.

Setting Organisations inspected by the Care Inspectorate in Scotland.

Population 13310 social care organisations (eg, nursing homes and day care organisations).

Primary outcomes The quality and risk domains collected by the Care Inspectorate and complaints and requirements issued to organisations within the last 3 years.

Results Controlling for multiple factors, we find that public and third sector providers performed consistently and statistically significantly better than for-profit organisations on most outcomes. For example, for-profit services were the most likely to be rated as high and medium risk $(6.9 \%$ and $13.2 \%$, respectively), and the least likely to be classified as low risk (79.9\%). Public providers had the highest probability of being categorised as low risk (91.1\%), and the lowest probability of having their services classified as medium (6.9\%) and high risk (2\%), followed by third sector providers ( $86 \%, 8.5 \%$ and $4.5 \%$, respectively). Public providers performed better than third sector providers in some outcomes, but differences were relatively low and inconsistent.

Conclusion Public and third sector providers were rated considerably higher than their for-profit counterparts on most observed outcomes. Regulators might use this information to consider how social care providers across sector are incentivised to manage their resources.

\section{INTRODUCTION}

Health and social care services are often delivered in quasi-markets, and an increasing
Strengths and limitations of this study

- The publically available data set provided by the Care Inspectorate allows for testing variation in quality-related outcomes across public, for-profit and third sector care providers in Scotland.

- The analysis aimed to replicate past research in a new context controlling for more factors (eg, number of staff) and on a broader range of outcomes (eg, user-reported complaints).

- There were few observations for organisations with very low quality levels, making comparison across sector difficult in these categories.

- The findings were consistent across the quality domains collected by the Care Inspectorate and as to whether requirements and complaints had been issued to organisations.

proportion of these services are implemented by for-profit organisations (FPOs) and third sector organisations (TSOs). ${ }^{1-4}$ Quasi-markets are characterised by free bidding from organisations across different sectors ${ }^{5}$ and can be defined as '... markets where the provision of a service is undertaken by competitive providers as in pure markets, but where the purchasers of the service are financed from resources provided by the state instead of from their own private resources'. ${ }^{6}$ Thus, quasi-markets primarily include services that are free or subsidised to service users (eg, healthcare or nursing homes), but where providers from all sectors (ie, public, for-profit and third) compete for service contracts.

It has been argued that quasi-markets can lead to more efficient and equitable service deliveries, ${ }^{57}$ but there is little conclusive evidence to support that proposition. In theory, quasi-markets may produce favourable outcomes, in that the bidding system can be thought to force organisations to respond to the needs of service users and allow the best and most innovative providers to attain the contract. However, the utility of this type 
Table 1 Theoretical distinction of sectors

\begin{tabular}{llll}
\hline & For-profit sector & Public sector & Third sector \\
\hline Definition & $\begin{array}{l}\text { Organisations that are privately } \\
\text { owned and administered } \\
\text { according to the pursuit of } \\
\text { profits. }\end{array}$ & $\begin{array}{l}\text { Organisations that are } \\
\text { publically owned and } \\
\text { administered. }\end{array}$ & $\begin{array}{l}\text { Organisations that are formally } \\
\text { structured, privately owned, non- } \\
\text { profit distributing, self-governing } \\
\text { and benefiting from voluntary } \\
\text { activities. }\end{array}$ \\
\hline Primary activities & $\begin{array}{l}\text { Conventionally private goods, } \\
\text { but increasingly also public } \\
\text { goods }\end{array}$ & Public goods & $\begin{array}{l}\text { Public goods } \\
\text { Main type of income }\end{array}$ \\
\hline Profits from sales of products \\
and/or services & Taxation & $\begin{array}{l}\text { Charitable contributions and/or } \\
\text { commissioning }\end{array}$ \\
\hline Maximise and sustain profits & $\begin{array}{l}\text { Achieve social mission (public } \\
\text { sechieve social mission and } \\
\text { accountability (social value) }\end{array}$ \\
\hline
\end{tabular}

of market strongly relies on the commissioning structures in place to allocate funding, which is known to have been flawed in the past. ${ }^{8-10}$ Further, it has long been understood that mechanisms of action considering behaviour and the design of social policy requires more than simply an analysis of monetary incentives. ${ }^{11}$

It has long been assumed that providers from different sectors are subject to different incentives and organisational characteristics. ${ }^{12-16}$ For example, FPOs are often perceived to be legitimised by the pursuit of profit maximisation, suggesting that they may engage in opportunistic behaviour at the potential expense of the service user without regulation. Conversely, TSOs and public sector organisations (PSOs) are often considered to be legitimised by their ability to achieve social value, suggesting that their incentive to deliver services are predominantly motivated by pro-social pursuits, thus, making them more 'trustworthy' providers of public services. ${ }^{17}$ These theoretical differences across sector are summarised in table 1.

Importantly, there is no general consensus on what these theoretical differences between sectors mean in practice and whether, and if so, how, they may relate to quality of service.

To explore sector differences in the context of health services, a relatively recent overview of systematic reviews investigated how ownership influences the performance of healthcare providers. ${ }^{18}$ The overview included 15 systematic reviews that were conducted in various contexts $(\mathrm{eg}$, low-income and middle-income countries and high-income countries) and with different types of providers (eg, hospitals and nursing homes). The paper found mixed results with non-profit providers performing better than for-profit providers on certain indicators (eg, mortality and price), but not on others (eg, healthcare-related outcomes). Further, the results should be interpreted with the caveat that most of the included systematic reviews had significant methodological flaws and only one of the reviews was considered 'reliable'. As a result, the overview concludes that more high quality primary research is needed, especially in exploring variation across PSOs,
FPOs and TSOs, rather than just between for-profit and non-profit providers. ${ }^{18}$

However, little research has been conducted on sector difference in social care settings, even though more social services are undertaken by for-profit and third sector providers, ${ }^{31920}$ and that sector variation in service quality thus have important implications for practice. To explore the merit of existing theories and to inform future policy on the contracting of social services, it is central to test whether the typology of sector accounts for variation across factors that matter to practice, such as quality and performance.

\section{Objectives}

It remains relatively inconclusive whether typology of sector is based on research conventions rather than empirical evidence. ${ }^{21}$ The focus of this paper will be to empirically test whether and if so how 'sector' accounts for variation in quality of social care organisations using data from the Care Inspectorate in Scotland. This focus can be summarised by the following research question:

Does the quality of social care services vary among for-profit, public and third sector organisations as assessed by the quality and risk domains of the Care Inspectorate in Scotland?

\section{Data: the Care Inspectorate}

The Care Inspectorate serves as the regulator of care services in Scotland and currently (January 2018) includes data on 13310 organisations, which is available for download on the official website and updated monthly. ${ }^{22}$ Regulated organisations work within a range of different services, with the biggest categories being childminding, children day care services, support services, care homes for the elderly and housing support (see tables A1-A2 in online supplementary appendix A for description of included services).

To fulfil its regulating role, the Care Inspectorate regularly inspects care facilities, which entails assessing the quality and risk of services. The grading of quality 
Table 2 Quality domains employed by the Care Inspectorate.

\begin{tabular}{ll}
\hline Quality and risk domains & Elaboration \\
\hline Quality of care and support & $\begin{array}{l}\text { How well does the service meet } \\
\text { the needs of the service users? } \\
\text { This includes looking at the } \\
\text { outcomes and materials of the } \\
\text { provided services and interviewing } \\
\text { service users. }\end{array}$ \\
\hline $\begin{array}{l}\text { Quality of management and } \\
\text { leadership }\end{array}$ & $\begin{array}{l}\text { How is the service managed } \\
\text { and does the strategy for } \\
\text { development consider the } \\
\text { needs of the service users? This } \\
\text { includes interviewing staff and } \\
\text { service users. }\end{array}$ \\
\hline $\begin{array}{l}\text { What is the quality of the setting in } \\
\text { which a service is delivered? This } \\
\text { includes investigating if the site is } \\
\text { clean and properly maintained. }\end{array}$ \\
$\begin{array}{l}\text { What is the quality of staff in terms } \\
\text { of, for example, qualifications and } \\
\text { training? This includes interviewing } \\
\text { staff and service users. }\end{array}$ \\
$\begin{array}{l}\text { A joint assessment of the nature } \\
\text { of the services (some services are } \\
\text { inherently more 'risky' than others), } \\
\text { if complaints have been issued } \\
\text { towards a service and whether any } \\
\text { requirements were posed after the } \\
\text { last inspection. }\end{array}$ \\
\hline Risk of services
\end{tabular}

is done according to the National Care Standards, ${ }^{23}$ which considers the following principles: 'dignity and respect'; 'compassion'; 'be inclusive', 'responsive care and support' and 'well-being'. The ratings are graded from 1 to 6 , in which 1 is unsatisfactory and 6 is excellent. Further, the Care Inspectorate distributes a risk score to care providers assessing whether a service can be said to be of 'low', 'medium' or 'high' risk to service users, which subsequently influences how regularly an organisation should be inspected and the quality domains to which the service should be subjected. ${ }^{24}$ The four quality domains and the risk assessment are described in table 2 .

The inspections are done by trained staff following a standardised procedure, which includes visiting the facility in question unannounced, conducting interviews with staff and service users, as well as physically examining the facilities. ${ }^{25}{ }^{26}$ Inspected organisations must also fill out a self-assessment form, which is reviewed in combination with the organisation's history of posed requirements and complaints as part of the grading process. Special guidelines apply to certain care services, such as organisations that work with children and young people. ${ }^{27}$

\section{METHODS}

This paper is reported following best practice guidelines. ${ }^{28} 29$ All analyses were conducted in Stata V.14.

The quality and risk domains collected by the Care Inspectorate are ordinal in nature and thus lend themselves to ordered logistic regression. However, this technique rests on the proportional odds or parallel lines assumption, which requires the effect of the odds to be constant across all logits. ${ }^{30}$ Substantively, this would mean that the effect of sector on quality would be constant across all levels of quality.

We tested this assumption across sector on the quality domains and risk assessment using the 'brant' command, ${ }^{31}$ which demonstrated the parallel lines assumption to be violated in three quality domains (except for quality of environment) and the risk assessment, thus suggesting that the effect of sector does vary across different levels of quality and risk. To use the ordering of the data, while also allowing for the proportional odds assumption to be relaxed, we employ generalised ordered logistic regression, which is less restrictive than ordered logistic regression and more suitable for non-linear associations. ${ }^{30}$ Specifically, we will use the gologit2 command written and regularly updated by Richard Williams. ${ }^{32}$

Logistic regression is known to entail several limitations, especially when it comes to accurately presenting and interpreting ORs. ${ }^{33}$ To demonstrate the effect of sector, we report results as predicted probabilities, which are often argued to be a more robust and intuitively interpretable effect size compared with ORs. ${ }^{34} 35$ Therefore, we will not report on the actual coefficients (although these can be found in online supplementary appendix B), but instead use the gologit2 output to compute non-linear probability models. $^{30}$

While marginal effects and predicted probabilities are not immune to unobserved heterogeneity, ${ }^{36}$ they are considered less sensitive to changes in the model specification than ORs. ${ }^{34}$ All predicted probabilities are derived following marginal standardisation, that is, as the average effect of sector on quality, as opposed to the effect of sector on quality on average (ie, prediction at the means). ${ }^{37} \mathrm{We}$ use the 'mtable' command to derive predicted probabilities, and the 'mchange' command to test if the changes in probability are statistically significant. ${ }^{38}$ All differences in probabilities are reported in percentage points rather than as relative differences.

\section{Explanatory variables}

The key explanatory variables are sector, which is coded as dummies: for-profit ('private'), public ('local authorities') and third sector ('voluntary or not for profit'), with FPOs as the benchmark category. We rely on the classification of service type provided by the Care Inspectorate and the analysis thus rests on the assumption that similarly classified service types do not differ systematically across sectors. However, to account for the possibility that the effect of sector varies according to different services, all service types are included as dummy variables. We exclude service types with very limited sector variation (ie, adoption services, adult placement services, childminding, fostering services, nurse agencies and offender accommodation services). We also ran the models on the largest subcategories of services to explore generalisability across 
included service types (ie, care home services, children day care services, housing support services and support services). To ensure that observed effects were not driven by experience of service providers, we control for the number of years of registration with the CI. Further, we include dummy variables for whether an organisation has improved, declined or stagnated in its lowest ranked category since the last inspection. Finally, we control for the client group of care organisations (eg, children, older people, dementia patients), whether an organisation is currently active, and the number of employed staff.

\section{Dependent variables}

The dependent variables of interest are the quality and risk domains described in table 2 . To test if sector predicts variation in regulation, we also investigate if organisations from different sectors vary in their probability to having been issued a requirement as a result of an inspection. Further, to ensure that the effect of sector on quality aligns to a user-reported outcome, we explore the probability of organisations having been subject to at least one complaint within the last 3 years.

Due to a limited number of observations in each group, we merged category 1 and 2 ('poor quality'), category 3 and 4 ('adequate quality') and category 5 and 6 ('high quality') across all quality domains. However, all reported analyses were also run on the original quality scores, which demonstrate similar results. Number of requirements and complaints were treated as binary variables (having received a requirement/complaint or not within last 3 years).

\section{Patient and public involvement}

Patients and public were not involved.

\section{RESULTS}

\section{Descriptive statistics}

The data set includes 8111 (60.94\%) FPOs, 2602 (19.55\%)

TSOs and 2597 (19.51\%) PSOs. Table 3 shows that FPOs have a higher number of employed staff on average, compared with PSOs and TSOs, but that the spread of observations for staff in FPOs is also the highest. TSOs have the highest proportion of organisations $(4.66 \%)$ which improved their minimum quality rating within the last month, although the difference between sectors is modest. PSOs have, on average, been registered the longest, whereas FPOs tend to have been registered for a shorter period than PSOs and TSOs.

Table 4 displays the cross tabulations of whether organisations have been subject to requirements after an inspection and if any complaints have been posed towards an organisation within the last 3 years. We see that PSOs received the fewest (proportionally) requirements (13.28\%) and that FPOs and TSOs receive similar numbers of requirements (18.31\% vs $19.43 \%)$. FPOs received a higher proportion of complaints compared with PSOs and TSOs, although the difference between the for-profit and third sector is relatively small $(10.84 \%$ vs $8.65 \%$ ).

Table 4 further shows that there is a roughly equal proportion of TSOs and FPOs with a 'poor' quality rating and that PSOs tend to have the lowest proportion of organisations in this category. However, more FPOs score 'adequately' relative to PSOs and TSOs, and, conversely, a higher proportion of PSOs and TSOs fall within the high-quality category, compared with FPOs. One exception is the 'quality of environment' domain, in which the proportions across different levels of quality is roughly similar across sector. PSOs have the highest proportion of 'low-risk' organisations, whereas TSOs seem to be of proportionally higher risk compared with PSOs and FPOs.

\section{Predicted probabilities}

Figure 1 shows the predicted probabilities of all outcome variables (the four quality domains, risk, requirements and complaints) across sector. The probabilities are derived from the generalised ordered logistic regression models, controlling for years of registration, type of

Table 3 Descriptive characteristics

\begin{tabular}{llll}
\hline & For-profit sector & Public sector & Third sector \\
\hline $\begin{array}{l}\text { Number of organisations } \\
\text { Active organisations }\end{array}$ & $8111(60.94 \%)$ & $2597(19.51 \%)$ & $2602(19.55 \%)$ \\
$\quad$ Active & $7891(97.29 \%)$ & $2572(99.04 \%)$ & $2566(98.62 \%)$ \\
$\quad$ Inactive & $220(2.71 \%)$ & $25(0.96 \%)$ & $36(1.38 \%)$ \\
Change in minimum quality rating in the last month & & & $2246(91.08 \%)$ \\
$\quad$ Same & $6576(93.44 \%)$ & $2363(93.14 \%)$ & $105(4.26 \%)$ \\
$\quad$ Decline & $215(3.05 \%)$ & $96(3.78 \%)$ & $115(4.66 \%)$ \\
$\quad$ Improve & $247(3.51 \%)$ & $78(3.07 \%)$ & $12.76(24.68)$ \\
$\quad$ Average number of staff & $14.56(31.87)$ & $10.62(27.27)$ & $11.53(4.90)$ \\
$\quad$ Average years of registration & $8.58(5.42)$ & $13.92(3.77)$ & \\
\hline
\end{tabular}

Percentages in parenthesis for number of organisations, active organisations and changes in minimum quality ratings. SD in parenthesis for the average number of staff and years of registration. 
Table 4 Cross tabulation of sector over quality domains, risk score and requirements/complaints posed after inspection within last 3 years

\begin{tabular}{|c|c|c|c|}
\hline & For-profit sector & Public sector & Third sector \\
\hline \multicolumn{4}{|c|}{ Quality of care $(n=12322)$} \\
\hline Poor quality & $57(0.78)$ & $10(0.39)$ & $20(0.80)$ \\
\hline Adequate quality & $2641(36.31)$ & $732(28.73)$ & $718(28.71)$ \\
\hline Good quality & $4575(62.90)$ & $1806(70.88)$ & $1763(70.49)$ \\
\hline \multicolumn{4}{|c|}{ Quality of staff $(n=7933)$} \\
\hline Poor quality & $59(2.04)$ & $8(0.31)$ & $25(1.00)$ \\
\hline Adequate quality & $1475(51.09)$ & $783(30.74)$ & 875 (35.01) \\
\hline Good quality & $1353(46.87)$ & $1756(68.94)$ & $1599(63.99)$ \\
\hline \multicolumn{4}{|c|}{ Quality of environment $(n=10293)$} \\
\hline Poor quality & $32(0.48)$ & $7(0.32)$ & $11(0.81)$ \\
\hline Adequate quality & $2515(37.58)$ & $759(35.60)$ & $553(40.84)$ \\
\hline Good quality & $4145(61.94)$ & $1408(64.77)$ & $790(58.35)$ \\
\hline \multicolumn{4}{|c|}{ Quality of management $(n=12386)$} \\
\hline Poor quality & $107(1.47)$ & $15(0.59)$ & $38(1.52)$ \\
\hline Adequate quality & $3642(50.12)$ & $1041(40.87)$ & $1033(41.83)$ \\
\hline Good quality & $3518(48.41)$ & $1491(58.54)$ & $1441(56.65)$ \\
\hline \multicolumn{4}{|c|}{ Risk of services $(n=13268)$} \\
\hline Low risk & $7263(89.96)$ & $2420(93.22)$ & $2259(86.95)$ \\
\hline Medium risk & $504(6.24)$ & $140(5.39)$ & $231(8.89)$ \\
\hline High risk & $307(3.8)$ & $36(1.39)$ & $108(4.16)$ \\
\hline \multicolumn{4}{|c|}{ Complaints received within last 3 years } \\
\hline No & $7233(89.16)$ & $2453(94.46)$ & $2377(91.35)$ \\
\hline Yes & $879(10.84)$ & $144(5.54)$ & $225(8.65)$ \\
\hline Total & 8112 & 2597 & 2602 \\
\hline \multicolumn{4}{|c|}{ Requirements posed after inspection within last 3 years } \\
\hline No & $4944(81.69)$ & $2025(86.72)$ & $1737(80.57)$ \\
\hline Yes & $1108(18.31)$ & $310(13.28)$ & 419 (19.43) \\
\hline Total & 6052 & 2335 & 2156 \\
\hline
\end{tabular}

Percentages in parentheses.

sector, whether an organisation is active, target group of service providers (eg, residents with dementia), type of service provider, number of employed staff and whether an organisation has improved, declined or stagnated in its lowest ranked quality category since the last inspection. The number of included observations in the generalised logistic models are lower than in table 5 due to the exclusion of service types with limited sector variation (ie, childminding, adoption services, adult placement services, nurse agencies and offender accommodation services). However, the observed effect of sector on quality remains similar when running more simple and inclusive models. For the binary outcome variables (complaints and requirements), the predicted probabilities are derived from multiple logistic regression models, controlling for the same variables as described above. To adjust for multiplicity, all displayed CIs are Bonferroni corrected.

\section{Differences between FPOs, PSOs and TSOs}

Figure 1 shows a similar pattern to the cross tabulations of quality across sector (see tables A3-A4 in supplementary appendix A for predicted probabilities). Again, FPOs are, in general, more likely to secure 'adequate' quality scores, but less likely to be in the 'high-quality' category, relative to PSOs and TSOs. For example, the predicted probability for FPOs to be in the 'high-quality' category in the care and support domain is $58.4 \%$, whereas it is $69.2 \%$ for PSOs and $66.8 \%$ for TSOs. The predicted probability for FPOs to be of 'adequate quality' in the same domain is $40.1 \%$ versus $30.3 \%$ for PSOs and $32.2 \%$ for TSOs.

In table 5, we see that the differences in predicted probabilities for 'adequate' and 'high' quality are 


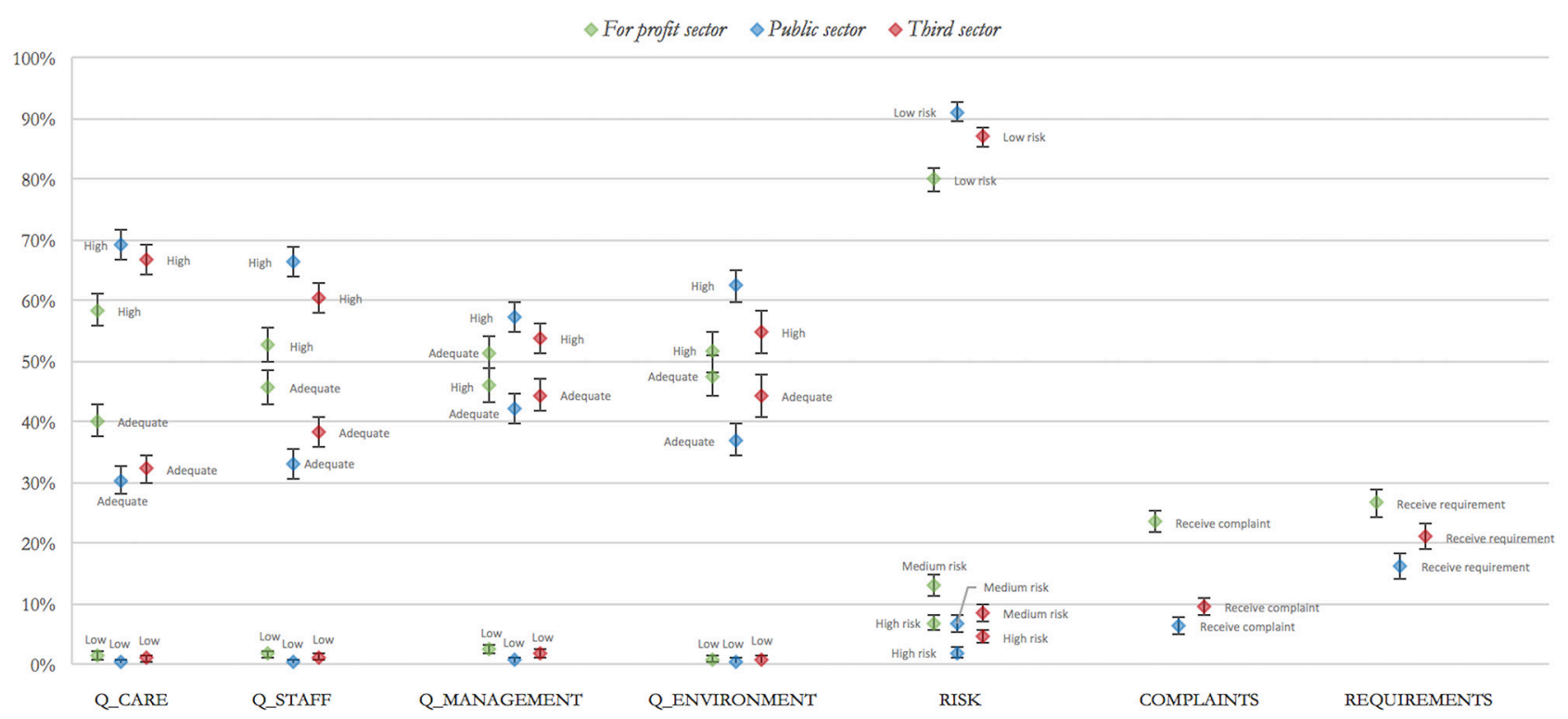

Figure 1 Predicted probabilities for the four quality domains, risk, complaints and requirements across sectors with $95 \%$ Cls. All quality outcomes are based on a scale of low, adequate and high quality. The risk outcome is based on a scale of low, medium and high risk. The complaint and requirement outcomes are binary with the predicted probabilities referring to the likelihood of having been issued a complaint or requirement within the last three years. All predicted probabilities are displayed in percentages.

mostly statistically significant for public and third sector providers, compared with FPOs. The only quality domain which did not display this pattern was 'quality of environment', in which the differences in predicted probabilities between FPOs and TSOs were not statistically significant. Further, FPOs were more likely to given a 'poor quality' rating compared with PSOs for 'quality of care', 'quality of staff' and 'quality of management', although the absolute differences are relatively small (below 2 percentage points). There were no statistically significant differences in the 'poor quality' rating between TSOs and FPOs.

\section{Differences between public and third sector providers}

We observe several significant differences in the probabilities between PSOs and TSOs, although the differences in probability are smaller compared with the for-profit sector. For 'quality of staff', 'quality of environment' and 'quality of management', PSOs were more likely to be in the high-quality category compared with TSOs $(66.4 \%$ vs $60.5 \%, 62.5 \%$ vs $54.8 \%$, and $56.2 \%$ vs $53.7 \%$, respectively). Similarly, TSOs were more likely to be rated of 'adequate quality' in 'quality of staff' $(38.3 \%)$ and 'quality of environment' (44.2\%) relative to PSOs $(33.72 \%$ and $37 \%$, respectively). For 'quality of care', 'quality of staff' and 'quality of management', TSOs are slightly, but statistically significantly, more likely to be in the low-quality group relative to PSOs (difference below 1.5 percentage points).

\section{Risk of services}

For-profit providers were the least likely to be classified as 'low-risk' services $(79.9 \%)$, and the most likely to be in 'medium-risk' (13.2\%) and 'high-risk' (6.9\%) groups.
PSOs had the highest probability of being categorised as 'low-risk' services $(91.1 \%)$, and the lowest probability of having their services classified as of 'medium' (6.9\%) and 'high risk' (2\%), followed by TSOs $(86 \%, 8.5 \%$, and $4.5 \%$, respectively). Most differences across the levels of risk between sectors were statistically significant, but the differences between PSO and TSOs were substantially smaller compared with TSOs versus FPOs and PSOs versus FPOs.

\section{Complaints and requirements}

Figure 1 shows the predicted probabilities for organisations to have been subject to a complaint or requirement in the last 3 years across sector. Again, we observe that FPOs are significantly more likely to having been issued at least one complaint, compared with PSOs and TSOs, with a difference of 17.1 and 14 percentage points, respectively (see table 6 ). Similarly, FPOs were more likely to having been subject to a requirement after inspection, relative to PSOs and TSOs with a difference of 10.5 percentage points for PSOs and FPOs, and 5.6 percentage points for TSOs and FPOs. PSOs were significantly more likely to having received a requirement or complaint relative to TSOs, but the differences were substantially smaller compared with FPOs.

\section{Other explanatory factors}

The number of years an organisation has been registered with the Care Inspectorate and the number of employed staff were both significant predictors of quality. The association between age and quality showed that the older the organisation, the higher 
Table 5 This table displays the difference in predicted probabilities across sectors over the quality and risk domains with $95 \% \mathrm{Cls}$

\begin{tabular}{|c|c|c|c|}
\hline & Low quality & Adequate quality & High quality \\
\hline \multicolumn{4}{|c|}{ Quality of care and support $(n=7011)$} \\
\hline Public versus for-profit sector & $-0.011^{\star \star \star}$ & $-0.098^{\star \star \star}$ & $0.108^{\star \star \star}$ \\
\hline $95 \% \mathrm{Cl}$ & -0.018 to -0.004 & -0.135 to -0.061 & 0.071 to 0.146 \\
\hline Third versus for-profit sector & -0.005 & $-0.079^{\star \star *}$ & $0.084^{\star \star \star}$ \\
\hline $95 \% \mathrm{Cl}$ & -0.014 to 0.003 & -0.116 to -0.042 & 0.047 to 0.121 \\
\hline Third versus public sector & 0.006 & 0.019 & -0.024 \\
\hline $95 \% \mathrm{Cl}$ & -0.001 to 0.012 & -0.015 to 0.053 & 0.010 to 0.261 \\
\hline \multicolumn{4}{|l|}{ Quality of staff $(n=7007)$} \\
\hline Public versus for-profit sector & $-0.013^{\star \star \star}$ & $-0.125^{\star \star \star}$ & $0.138^{\star \star \star}$ \\
\hline $95 \% \mathrm{Cl}$ & -0.020 to -0.006 & -0.164 to -0.087 & 0.100 to 0.177 \\
\hline Third versus for-profit sector & -0.005 & $-0.074^{\star \star \star}$ & $0.079^{\star \star \star}$ \\
\hline $95 \% \mathrm{Cl}$ & -0.014 to 0.004 & -0.112 to -0.036 & 0.041 to 0.117 \\
\hline Third versus public sector & $0.008^{*}$ & $0.051^{*}$ & $-0.059^{\star \star \star}$ \\
\hline $95 \% \mathrm{Cl}$ & 0.002 to 0.015 & 0.015 to 0.086 & -0.095 to -0.023 \\
\hline \multicolumn{4}{|l|}{ Quality of environment $(n=5099)$} \\
\hline Public versus for-profit sector & -0.003 & $-0.106^{\star \star \star}$ & $0.110^{\star \star \star}$ \\
\hline $95 \% \mathrm{Cl}$ & -0.010 to 0.004 & -0.151 to -0.061 & 0.065 to 0.154 \\
\hline Third versus for-profit sector & 0.001 & -0.034 & 0.033 \\
\hline $95 \% \mathrm{Cl}$ & 0.004 to 0.010 & -0.082 to 0.015 & 0.015 to 0.081 \\
\hline Third versus public sector & 0.004 & $0.073^{\star \star \star}$ & $-0.077^{* * *}$ \\
\hline $95 \% \mathrm{Cl}$ & -0.004 to 0.012 & 0.030 to 0.115 & -0.119 to -0.034 \\
\hline \multicolumn{4}{|l|}{ Quality of management $(n=7004)$} \\
\hline Public versus for-profit sector & $-0.019^{\star * \star}$ & $-0.093^{\star \star *}$ & $0.112^{\star \star \star}$ \\
\hline $95 \% \mathrm{Cl}$ & -0.028 to -0.010 & -0.133 to -0.133 & 0.073 to 0.152 \\
\hline Third versus for-profit sector & -0.007 & $-0.070^{\star \star \star}$ & $0.077^{\star \star \star}$ \\
\hline $95 \% \mathrm{Cl}$ & -0.018 to 0.004 & -0.109 to -0.031 & 0.039 to 0.116 \\
\hline Third versus public sector & $0.012^{* * *}$ & 0.023 & -0.035 \\
\hline \multirow[t]{2}{*}{$95 \% \mathrm{Cl}$} & 0.004 to 0.020 & -0.014 to 0.060 & -0.072 to 0.002 \\
\hline & Low Risk & Medium Risk & High Risk \\
\hline \multicolumn{4}{|l|}{ Risk of services $(n=7335)$} \\
\hline Public versus for-profit sector & $0.112^{* \star *}$ & $-0.063^{\star \star \star}$ & $-0.049^{\star \star \star}$ \\
\hline $95 \% \mathrm{Cl}$ & 0.086 to 0.138 & 0.086 to -0.040 & -0.064 to -0.034 \\
\hline Third versus for-profit sector & $0.071^{\star \star *}$ & $-0.047^{\star * *}$ & $-0.024^{*}$ \\
\hline $95 \% \mathrm{Cl}$ & 0.045 to 0.098 & -0.071 to -0.024 & -0.041 to -0.007 \\
\hline Third versus public sector & $-0.041^{\star \star \star}$ & 0.016 & $0.025^{\star \star \star}$ \\
\hline $95 \% \mathrm{Cl}$ & -0.063 to -0.018 & -0.004 to 0.036 & 0.012 to 0.038 \\
\hline
\end{tabular}

${ }^{*} \mathrm{p}<0.05 ;{ }^{* * *} \mathrm{p}<0.001$. Also, higher values of risk indicate higher risk of services.

probability of being rated of high quality. Further, the more paid staff an organisation had, the more likely an organisation was to be in the 'adequate' category, whereas the probability of being in the 'high-quality' category decreased with the number of employed staff. Neither the effects of staff and time in operation on quality were interacted by sector.

\section{Subanalyses}

We reran the analyses on the biggest subgroups of services (ie, care homes, support services, child care services and housing support services), which can be found in in table A5 in the online supplementary appendix A and figures B1-B5 in the online supplementary appendix C. Most of these subanalyses resulted in slightly reduced effects 


\begin{tabular}{|c|c|c|}
\hline & & $95 \%$ Cls \\
\hline \multicolumn{3}{|c|}{ If a complaint has been issued within last 3 years $(n=7358)$} \\
\hline Public versus for-profit sector & $0.171^{\star \star \star}$ & 0.197 to 0.144 \\
\hline Third versus for-profit sector & $0.140^{\star \star *}$ & 0.167 to 0.112 \\
\hline Third versus public sector & $-0.031^{\star \star \star}$ & -0.012 to -0.050 \\
\hline \multicolumn{3}{|c|}{$\begin{array}{l}\text { If a requirement has been issued after inspection within last } \\
3 \text { years }(n=6320)\end{array}$} \\
\hline Public versus for-profit sector & $0.105^{\star \star \star}$ & 0.138 to 0.072 \\
\hline Third versus for-profit sector & $0.056^{\star * \star}$ & 0.138 to 0.072 \\
\hline Third versus public sector & $-0.049^{\star \star \star}$ & -0.019 to -0.079 \\
\hline
\end{tabular}

of sector and with less clear differences between PSOs and TSOs. However, both the raw cross tabulations and the predicted probabilities generally display the same substantive pattern and direction of effects with FPOs being more likely to be classified as of adequate quality and of higher risk relative to TSOs and PSOs, which are more likely to be rated as high quality and of lower risk.

\section{DISCUSSION}

The present study finds that public and third sector providers are more likely to be rated of high quality and of lower risk compared with FPOs, which are more likely to be rated of adequate quality and of higher risk. This pattern was similarly observed in FPOs being more likely to receive requirements and complaints compared with their public and third sector counterparts.

The results can be thought to correspond with the notion that TSOs and PSOs are primarily driven by pro-social values and will thus be more motivated to maximise quality of services. Conversely, it may be contended that rational FPOs, being primarily motivated by profits, will coordinate their resources so that services fall within adequate standards. While PSOs were often less likely to be rated of 'low quality' relative to TSOs and FPOs, sector was generally not a strong predictor of the likelihood of organisations being given 'low quality' rating, which may be understood as all sectors being similarly incentivised not to be rated below acceptable threshold.

These findings echo a recent study on the quality of nursing homes, which utilised data from the Care Quality Commission (CQC) in England and Wales to test whether quality ratings varied according to sector finding that third and public providers were significantly more likely be rated of higher quality than FPOs, as measured by the quality index of the CQC. ${ }^{39}$ However, contrary to our findings, the paper did not identify any statistically significant differences between third and public sector nursing homes.

\section{Strengths and limitations}

This study adds to the existing research in several ways. First, the present study replicated results of past research in a new context controlling for more factors (eg, number of staff) and on a larger range of outcomes (eg, user-reported complaints) than in prior research. Second, the effect of sector on quality were robust to subsequent subanalyses and may thus be thought to generalise across the included types of care services in the Scottish context. Further, contrary to existing research, the study identified several significant differences between PSOs and TSOs, which often favoured the performance of PSOs. Yet, these differences in quality were substantially smaller compared with for-profit versus public and third sector providers.

This study is subject to several limitations, some of which are due to the nature of the data. For example, the lack of effect of sector on quality for levels of low quality (1-2) may be driven by the low number of observations in these categories. However, that origin of sector had no effect on quality is consistent to the idea that organisations from different sectors will, theoretically, have a similar disincentive to be rated as inadequate.

A more substantial limitation of the analysis is that service types may differ systematically across sectors. For example, it may be that clients served by FPOs are inherently different from those served by third and public sector providers. To address this issue, we controlled for all organisational characteristics allowed for by the data (eg, service types, years of registration and number of employees) and ran the models separately on all major service types, showing the same substantive pattern as reported in the main results. Although all models adjusted for the types of clients served by the social care providers (eg, children, older people, dementia patients), the data collected by the Care Inspectorate do not include individual-level information on clients served, and we could thus not investigate client variation in terms of, for example, socioeconomic status across sectors. To the best of our knowledge, there is no existing research investigating client variation across sectors for social care services, ${ }^{3} 3940$ which is important to explore in future research.

The analysis is built on the assumption that the quality ratings by the Care Inspectorate can be considered reliable indicators for the latent construct of 'quality', which may be a flawed assumption. Yet, the observed effects were consistent across different quality domains, which suggest that the effects of sector were-at least-robust to the construct of quality employed by the Care Inspectorate. Also, the pattern observed for the quality and risk domains was consistent with the inspection requirements and complaints outcomes.

Last, the results should be interpreted in the light of the context of the data. The analysis was conducted on Scottish data on certain types of care services and the findings therefore primarily apply to that context. To test whether the observed effects do indeed transfer to other countries and service settings (eg, healthcare), further research must replicate these analyses using comparable outcomes. 


\section{Implications for policy and practice}

Research on the typology of sector tend to be based on theory with limited attention on what the features distinct to each sector mean in practice and whether they influence aspects such as service delivery. Importantly, the findings of this paper do not indicate that services by FPOs are poor; in fact, the findings demonstrate that origin of sector was, for the most part, not a strong predictor of whether care organisations performed below acceptable standards. Also, similar to past research, the findings do not imply a causal effect of sector due to the observational nature of the data. ${ }^{41}$ However, the findings can be interpreted to imply that care organisations driven by pro-social motivations tend to perform better than those that are not, although this remains a theoretical interpretation, as the analysis does not include a concrete measure of motive. Going forward, it is essential to explore mechanisms to investigate whether the association found in this analysis is spurious or indeed the result of some sector-specific traits.

\section{CONCLUSION}

This paper investigated if origin of sector influence the quality of social care services regulated by the Care Inspectorate in Scotland to find that providers from the third and public sectors were rated of higher quality and lower risk than for-profit providers. Importantly, the analysis does not provide any empirical answer to why differences across sectors are observed. Although the results are consistent with theory and past research, more research is needed to explore what exact characteristics account for the variation in quality observed across sectors. From the findings, it follows that regulators and policymakers should incorporate more thought on how organisations across different sectors are incentivised to manage their resources, as this might influence the subsequent performance of commissioned services. However, there is little research addressing how this is best realised in practice, which warrant further analysis.

Acknowledgements The authors would like to express their gratitude to Caspar Kaiser, Bastian Betthäuser, Jonathan Klüser, Ani Movsisyan, Thees Spreckelsen, Peter Bach-Mortensen, and Professor Kimberly Scharf for their invaluable feedback on earlier drafts of the manuscript. We would also like to thank the reviewers for their helpful comments, which improved the manuscript substantially.

Contributors The research design and objectives were developed by AMB-M and PM. AMB-M designed and conducted the statistical analysis and drafted the manuscript with input from PM. All authors read and approved the final manuscript.

Funding The authors have not declared a specific grant for this research from any funding agency in the public, commercial or not-for-profit sectors.

Competing interests None declared.

Patient consent for publication Not required.

Provenance and peer review Not commissioned; externally peer reviewed.

Data sharing statement All data generated or analysed during this study is publically available or attached in the supplementary files.

Open access This is an open access article distributed in accordance with the Creative Commons Attribution Non Commercial (CC BY-NC 4.0) license, which permits others to distribute, remix, adapt, build upon this work non-commercially, and license their derivative works on different terms, provided the original work is properly cited, appropriate credit is given, any changes made indicated, and the use is non-commercial. See: http://creativecommons.org/licenses/by-nc/4.0/.

\section{REFERENCES}

1. Dickinson $\mathrm{H}$, Allen $\mathrm{K}$, Alcock $\mathrm{P}$, et al. The role of the third sector in delivering social care: NIHR School for Social Care Research, 2012.

2. Macmillan R. The third sector delivering public services: an evidence review. Birmingham: TSRC Working Paper 20, University of Birmingham, 2010.

3. Comondore VR, Devereaux PJ, Zhou Q, et al. Quality of care in for-profit and not-for-profit nursing homes: systematic review and meta-analysis. BMJ 2009;339:b2732-32.

4. Tynkkynen LK, Vrangbæk K. Comparing public and private providers: a scoping review of hospital services in Europe. BMC Health Serv Res 2018;18:141.

5. Le GJ, Le Grand J. Quasi-markets and social policy. Econ J $1991 ; 101$.

6. Le Grand J. Quasi-Market versus state provision of public services : some ethical considerations. Public Reason 2011;3:80-9.

7. NHS. The Role of Private Non-For Profit Healthcare Organisations in the NHS system: implications for the portuguese Hospital Devolution Program. 2016;577 http://wps.fep.up.pt/wps/wp577.pdf

8. Pritchett $L$. It pays to be ignorant: A simple political economy of rigorous program evaluation. The Journal of Policy Reform 2002;5:251-69.

9. Chapman T, Bell V, Robinson F. Measuring impact: easy to say hard to do: a think-piece to stimulate sector debate from the Third Sector Trends Study. 2011;17.

10. Harlock J. From outcomes-based commissioning to social value? Implications for performance managing the third sector. Birmingham: TSRC Working Paper 123, University of Birmingham, 2014.

11. Titmuss RM. The gift relationship: from human blood to social. London: George Alien \& Unwin Ltd, 1970.

12. Hardwick R, Anderson R, Cooper C. How do third sector organisations use research and other knowledge? A systematic scoping review. Implement Sci 2015;10:84.

13. Moore MH. Managing for value: organizational strategy in for-profit, nonprofit, and governmental organizations. Nonprofit Volunt Sect $Q$ 2000;29:183-204.

14. Anheier HK. Theory nonprofit organizations management, policy: Routledge, 2005.

15. Alcock P. A strategic unity: defining the third sector in the UK. Voluntary Sector Review 2010;1:5-24.

16. Macmillan R. The third sector delivering public services: an evidence review. Policy Press 2010.

17. Witesman EM, Fernandez S. Government contracts with private organizations: are there differences between nonprofits and forprofits? Nonprofit Volunt Sect Q 2013;42:689-715.

18. Herrera CA, Rada G, Kuhn-Barrientos L, et al. Does ownership matter? An overview of systematic reviews of the performance of private for-profit, private not-for-profit and public healthcare providers. PLoS One 2014;9:e93456.

19. Kelly J. Reforming public services in the UK: Bringing in the third sector. Public Adm 2007;85:1003-22.

20. Cabinet Office. Open Public Services: White Paper. 2011 http:// www.cabinetoffice.gov.uk/sites/default/files/resources/open-publicservices-white-paper.pdf\%5Cnhttp://www.openpublicservices. cabinetoffice.gov.uk/.

21. Kramer RM. A Third sector in the third millennium? Voluntas: Int $J$ of Voluntary and Nonprofit Organizations 2000;11:1-23.

22. Datastore. Publications and statistics. http://www.careinspectorate. com/index.php/statistics-and-analysis/data-and-analysis (Accessed 26 Jan 2018).

23. New Care Standards. New Care Standards | Review of Scotland's National Care Standards. 2017 http://www.newcarestandards.scot/ (Accessed 30 Aug 2017).

24. Care Inspectorate. Risk Assessment - information for care service providers. 2017 http://www.careinspectorate.com/images/ documents/148/Risk\%20Assessment $\% 20 \%$ E2\%80\%93\% 20Information\%20for\%20Care\%20Service\%20Providers.pdf (Accessed 28 Aug 2017).

25. Care Inspectorate. How we inspect: What goes into our inspection reports for care services. 2013.

26. Inspectorate C. Inspections. http://www.careinspectorate.com/index. php/inspections (Accessed 9 Feb 2018).

27. Care Inspectorate. Inspection Handbook. 109, 2016. 
28. Vandenbroucke JP, Von Elm E, Altman DG, et al. Strengthening the Reporting of Observational Studies in Epidemiology (STROBE): Explanation and elaboration for the STROBE Initiative, 2014.

29. von Elm E, Altman DG, Egger M, et al. The strengthening the reporting of observational studies in epidemiology (strobe) statement: guidelines for reporting observational studies. Prev Med 2007;45:247-51.

30. Williams R. The Journal of Mathematical Sociology Understanding and interpreting generalized ordered logit models Understanding and interpreting generalized ordered logit models. J Math Sociol 2016;40:7-20.

31. Brant R. Assessing proportionality in the proportional odds model for ordinal logistic regression. Biometrics 1990;46:1171.

32. Williams R. gologit2 documentation. Stata J 2006;6 http://www.nd. edu/ rwilliam/gologit2/gologit2.pdf

33. Mood C. Logistic regression: why we cannot do what we think we can do, and what we can do about it. Eur Sociol Rev 2010;26:67-82.

34. Norton EC, Dowd BE. Log odds and the interpretation of logit models. Health Serv Res 2018;53:859-78.

35. Norton EC. Log Odds and Ends. 2012.
36. Skopek J, Hammer O. Different nails - a note on the confusing sociologists' debate on comparing coefficients in logistic regression. 2015.

37. Muller CJ, MacLehose RF. Estimating predicted probabilities from logistic regression: different methods correspond to different target populations. Int J Epidemiol 2014;43:962-70.

38. Long JS, Freese J. Regression models for categorical dependent variables using Stata. $2014 \mathrm{http} / / /$ ideas.repec.org/b/tsj/spbook/ long2.html

39. Barron DN, West E. The quasi-market for adult residential care in the UK: Do for-profit, not-for-profit or public sector residential care and nursing homes provide better quality care? Soc Sci Med 2017;179:137-46.

40. Hjelmar U, Bhatti $\mathrm{Y}$, Petersen $\mathrm{OH}$, et al. ublic/private ownership and quality of care: evidence from danish nursing homes the involvement of private for-profit (FP) and not-for-profit (NFP) providers in the. 2018.

41. Konetzka RT. Do not-for-profit nursing homes provide better quality? BMJ 2009;339:b2683.

42. Salamon LM, Anheier HK. In search of the non-profit sector. I: the question of definitions. Voluntas 1992;3:125-51. 